\title{
Uma nova escola médica para um novo sistema de saúde Saúde e Educação lançam programa para mudar o currículo de medicina
}

\author{
A new medical school for a new health system \\ Ministries of Health and Education are launching plan to change the \\ medical curriculum
}

\author{
Projeto Promoção da Saúde \\ Secretaria de Políticas de Saúde/MS*
}

\section{INTRODUÇÃO}

Os Ministério da Saúde e o Ministério da Educação instituem o Programa Nacional de Incentivo a Mudanças Curriculares nos Cursos de Medicina (Promed Portaria Interministerial ${ }^{\circ} 610$, em 26 de março de 2002) com o objetivo de incentivar as escolas médicas, de todo o país, a incorporar mudanças pedagógicas significativas nos currículos dos cursos de medicina.

O momento atual é particularmente oportuno para propor um sistema de incentivos às instituições acadêmicas que se disponham a adequar a formação profissional que oferecem às necessidades do SUS. Nessa primeira etapa, a proposta dirige-se às escolas médicas, por ser nessa categoria profissional que se apresentam os maiores problemas de formação, com forte tendência à especialização precoce, gerando um perfil profissional inadequado às perspectivas da atenção básica.

Uma das maiores preocupações que levam à proposição de mudanças na formação desses profissionais de saúde é a excessiva especialização médica, o que contribui para o aumento dos custos assistenciais e diminui, aos poucos, a figura do médico generalista, essencial para a ampliação dos programas de atenção básica, como o Programa Saúde da Família (PSF), que, atualmente, conta com aproximadamente 15 mil equipes atuando em todos os estados do país, atendendo quase 50 milhões de brasileiros. Até o final deste ano, serão 20 mil equipes de Saúde da Família. O orçamento do programa, para 2002, é de $\mathrm{R} \$ 1,3$ bilhão.

As mudanças sugeridas pelo Promed baseiam-se no fato de que os recém-graduados em medicina, no Brasil, dominam apenas metade dos conhecimentos que deveriam ter ao término do curso, de acordo com a Comissão Interinstitucional Nacional de Avaliação do Ensino Médico (Cinaem). O estudo da comissão conclui que a residência médica incorporou-se como uma continuidade natural da graduação, já que dois terços dos médicos que se formam ingressam na residência médica a fim de obter especialização, número que teve significativa ampliação nos últimos anos.

Iniciativas como o Promed já foram realizadas em países da Europa, no Canadá e nos Estados Unidos. O principal objetivo do programa é adequar a formação dos médicos à realidade do atual sistema de saúde brasileiro, já que os currículos das escolas de medicina praticamente não foram alterados nos últimos 30 anos.

\section{OBJETIVOS}

O Promed apresenta uma proposta de intervenção no processo formativo para que os programas de graduação possam deslocar o eixo da formação médica - centrado na assistência individual prestada em unidades hospitalares - para um outro em que a formação esteja sintonizada com o SUS, em especial com a atenção básica - considerando as dimensões sociais, econômicas e culturais que se fazem presentes no processo de adoecimento humano -, no sentido de instrumentalizar os profissionais para enfrentar os problemas do binômio saúde-doença da população nas esferas familiar e comunitária, e não apenas na instância dos serviços. Para tanto, coloca, como objetivos específicos:

- estabelecer, de forma sistemática e auto-sustentável, protocolos de cooperação entre os gestores do SUS e as escolas médicas;

- deslocar o eixo central do ensino médico da idéia exclusiva da enfermidade, incorporando noção integralizadora do processo saúde/doença e da promoção da saúde, com ênfase na atenção básica;

- propiciar a ampliação dos cenários e da duração da prática educacional na rede de serviços básicos de saúde;

- favorecer a adoção de metodologias pedagógicas ativas e centradas nos estudantes, visando preparálos para a auto-educação permanente num mundo de constante renovação da ciência. 


\section{CARACTERÍSTICAS}

Para viabilizar as mudanças nos currículos das escolas médicas, o programa estará investindo $\mathrm{R} \$ 8 \mathrm{mi}-$ lhões até 2003. Inicialmente foram selecionadas 20 escolas médicas que receberão recursos financeiros de acordo com cada projeto apresentado. As escolas selecionadas pelo programa receberão incentivos financeiros para contratação de consultores, realização de oficinas, requalificação dos docentes e compra de material de ensino.

A construção de um novo modelo pedagógico, de acordo com o preconizado no Promed, deve ter como perspectiva o equilíbrio entre excelência técnica e relevância social, configurados como princípios norteadores do movimento de mudança. Tal movimento deve estar sustentado na integração curricular, em modelos pedagógicos mais interativos, na adoção de metodologias de ensino-aprendizagem centradas no aluno como sujeito da aprendizagem e no professor como facilitador do processo de construção do conhecimento. Nesse sentido, o programa recomenda que as novas interações devam estar sustentadas em relações de parceria entre as universidades, os serviços e os grupos comunitários, como forma de garantir o planejamento do processo ensino-aprendizagem, focalizados em problemas sanitários prevalentes.

Esse processo, protagonizado pelo Promed, potencializa-se com os movimentos que ocorrem dentro do MEC: a Lei de Diretrizes e Bases da Educação Nacional, que, ao substituir o currículo mínimo pelas diretrizes curriculares, flexibiliza o processo de ensino e abre campo para que as escolas se transformem, e as Diretrizes Curriculares dos Cursos Médicos, que, coincidindo com a proposta do Promed, reafirmam: estes cursos devem formar profissionais com competência para terem postura ética; visão humanística, senso de responsabilidade social e compromisso com a cidadania; orientação para a proteção, promoção da saúde e prevenção das doenças; orientação para atuar em nível primário e secundário de atenção e resolver com qualidade os problemas prevalentes de saúde.

O Ministério da Saúde, com o Promed, coloca como necessário que os hospitais universitários e de ensino, as instituições de ensino superior (IES) e os gestores do sistema educacional devem buscar sua inserção - mais orgânica e efetiva - no SUS, criando condições reais para o exercício de sua missão e a retribuição, com a qualidade técnica que possui, na assistência, no ensino, na pesquisa, na educação - continuada e permanente e na avaliação da incorporação de novas tecnologias.

Para adequar o médico a essa nova realidade, o programa recomenda as seguintes mudanças pedagógicas:

- ênfase na medicina preventiva, valorizando o conceito de saúde em detrimento da doença;
- valorização da humanização do atendimento com formação de uma base ética sólida;

- incentivo ao ingresso dos futuros médicos em ações de atenção básica, dando prioridade ao programa;

- promoção da abertura dos serviços universitários à demanda do SUS.

A proposta visa a apoiar as escolas médicas que queiram, voluntariamente, adequar seus processos de ensino, produção de conhecimento e de serviços às necessidades do sistema de saúde brasileiro, com o que estará se voltando às necessidades sociais e epidemiológicas da maioria da população brasileira. $\mathrm{O}$ objetivo dessa iniciativa é estimular essas instituições de ensino a atender, simultaneamente, aos ditames da excelência técnica e da relevância social.

As escolas médicas que fizerem sua adesão podem elaborar projetos específicos de apoio às iniciativas de mudanças curriculares. Nesse sentido, são definidos termos de compromisso que são pactuados com o Ministério da Saúde e com os gestores estaduais e municipais do SUS.

\section{ESTRATÉGIAS}

Para a consecução dos objetivos propugnados no Promed e a criação de condições que favoreçam o alcance da situação desejada, propõe-se a instituição de um sistema de incentivos às instituições de ensino superior que adotem práticas de ensino, pesquisa e de atenção à saúde sintonizadas com o paradigma da integralidade.

A perspectiva é que os processos de mudança ocorram simultaneamente em distintos eixos, em direção a um dos aspectos da situação desejada apontada anteriormente, que antevê a IES integrada e que dê respostas às necessidades concretas do SUS na formação de recursos humanos, na produção de conhecimento e na prestação de serviços.

Nesse sentido, são propostos três eixos - orientação teórica, abordagem pedagógica e cenários de prática -, norteadores do processo de mudança curricular com vistas a atender as necessidades concretas do SUS na formação de recursos humanos, na produção do conhecimento e na prestação de serviços.

Esses três eixos mostram-se de acordo com a tendência que caracteriza a inovação dos processos de educação médica em todo o mundo. Cada eixo é decomposto em dois vetores, e, em cada um destes vetores, trata-se de fazer uma tipificação das escolas em três estágios, que partem de uma situação mais tradicional ou conservadora, no estágio 1 , até alcançar, no estágio 3, a situação-objetivo desejada.

O processo de transformação curricular, portanto, deverá ser avaliado em função do alcance de 
cada um desses estágios, em cada eixo proposto. Para tal, recomenda-se a conjugação de duas avaliações, uma interna e outra feita por consultores externos, que estabeleçam a situação atual, como um base-line para o processo de mudança. Definida a imagem-objetivo a ser alcançada, elaborar-seá um projeto para o qual se alocarão os recursos necessários, estabelecendo-se, a partir daí, um processo de acompanhamento externo que, somado à auto-avaliação, estabelecerá um acompanhamento contínuo desse processo de mudança.

Para facilitar o entendimento, os eixos, vetores e estágios encontram-se descritos a seguir.

\section{Eixo A - Orientação teórica}

Esse eixo comporta dois vetores que dizem respeito, respectivamente, à produção de conhecimentos e à oferta de pós-graduação e de educação permanente. Nesse âmbito, devem ser promovidos, com a capacidade existente, estudos clínico-epidemiológicos, ancorados em evidência capazes de possibilitar a avaliação crítica e de redirecionar protocolos e intervenções.

Devem ser também investigados componentes gerenciais do SUS, que possam estabelecer boas práticas de gestão, visando alimentar o processo de tomada de decisão e estimular a conformação de redes de cooperação técnica horizontal. Ao mesmo tempo, observa-se, com muita freqüência, que a oferta pelas IES de cursos para especialistas é condicionada pela lógica interna da instituição - pressão de grupos de poder, influência das corporações etc. -, e não pelas necessidades epidemiológicas e sociais. Assim, a oferta de pós-graduação e de processos de educação permanente com os serviços, para a área da atenção básica, tende a ser subestimada.

É necessário, portanto, que se articule cada vez mais a oferta de educação permanente com as necessidades assistenciais, incentivando-se a incorporação de modalidade de educação à distância, bem como oferta de vagas de cursos de pós-graduação em áreas estratégicas e ou carentes de profissionais qualificados para o SUS.

\section{Vetor 1: produção de conhecimentos segundo as necessidades do SUS}

- Estágio 1: escolas que não tenham produção sistemática de investigação em atenção básica ou que apenas tenham produção na área da atenção hospitalar e de alta tecnologia;

- Estágio 2: escolas que tenham baixa produção de investigações relacionadas à atenção básica ou com à gestão do SUS;

- Estágio 3: escolas com alta produção de investigações orientadas às necessidades da atenção básica, sem prejuízo da investigação pura e tecnológica, e que tenham forte interação com os serviços da saúde na área de produção e avaliação de protocolos clínicos, inovações da gestão, análises de custobenefício e outras assemelhadas.

\section{Vetor 2: pós-graduação e educação permanente}

- Estágio 1: oferta exclusiva de especialidades e ausência de oferta de especialização em atenção básica e de educação permanente aos profissionais da rede do SUS;

- Estágio 2: conformação intermediária, em que há esforços para a oferta de educação permanente relacionado à nosologia prevalente, mas não há questionamentos do perfil de oferta de residência médica, mestrados e doutorados, que seguem a lógica da especialização;

- Estágio 3: lógica da oferta de oportunidades educacionais feita em estreita articulação com os gestores do SUS; são revisados os quantitativos e a qualidade da formação, há um trabalho em estreita articulação com os Pólos de Capacitação em Saúde da Família.

\section{Eixo B - Abordagem pedagógica}

Esse eixo comporta também dois vetores, que são a mudança pedagógica e, como um caso particular deste, a integração entre o ciclo básico e o ciclo profissional.

O processo de educação de adultos pressupõe a utilização de metodologias ativas de ensino-aprendizagem que proponham concretamente desafios a ser superados pelos estudantes, que lhes possibilitem ocupar o lugar de sujeitos na construção dos conhecimentos e que coloquem o professor como facilitador e orientador desse processo.

Considerando-se a velocidade vertiginosa com que se produzem e são colocados à disposição conhecimentos e tecnologias no mundo atual, um dos objetivos fundamentais de aprendizagem do curso de graduação é o de aprender. Isto requer o desenvolvimento de habilidades em livros, periódicos, bases de dados locais e remotas, além da utilização das fontes pessoais de informação, incluindo a advinda de sua própria experiência profissional.

Um outro conceito-chave de um modelo pedagógico inovador é o de aprender fazendo, que pressupõe a inversão da seqüência clássica teoria/prática na produção do conhecimento, assumindo que ele aconteça de forma dinâmica por intermédio da ação-reflexão-ação. Pretende-se a completa integração entre os atuais ciclos básico e clínico e a adoção de um currículo integrado, organizado em módulos interdisciplinares, compostos por problemas relevantes e mais prevalentes. A resolução dos problemas é que orientará a busca da ciência básica que respalda as intervenções para enfrentá-los.

\section{Vetor 3: mudança pedagógica}

- Estágio 1: ensino centrado no professor, realizado fundamentalmente por meio de aulas 
expositivas para grandes grupos de estudantes, baseado em disciplinas estanques e com processos de avaliação baseados em testes e provas;

- Estágio 2: ensino que inclui inovações pedagógicas em caráter experimental restritas a certas disciplinas, realizado majoritariamente em pequenos grupos de até 15 estudantes, adotando processos de avaliação interativos, mas ainda restritos a menos de $20 \%$ da carga horária;

- Estágio 3: baseado majoritariamente em resolução de problemas, em grupos pequenos, em que os professores trabalham como tutores, ocorrendo o ensino em ambientes diversificados - bibliotecas, comunidade, laboratórios de simulação - e com atividades estruturadas a partir das necessidades de saúde que se apresentam ao SUS. Avaliação formativa e somativa, avaliando todos os aspectos da formação do estudante (conhecimentos, atitudes e habilidades).

\section{Vetor 4: integração ciclo básico/ciclo profissional}

- Estágio 1: ciclos clínico e básico completamente separados, com disciplinas fragmentadas;

- Estágio 2: existência de disciplinas/atividades integradoras ao longo dos primeiros anos, mas sendo mantida a organização por disciplinas e a separação dos conteúdos básicos e clínicos;

- Estágio 3: ensino majoritariamente integrado, em que é eliminada a precedência cronológica do ciclo básico, servindo as áreas básicas como retaguarda e referência para a busca dos conhecimentos para a solução de problemas, sem estruturação em disciplinas.

\section{Eixo C - Cenário de práticas}

Esse eixo compõe-se de dois vetores: os cenários de prática e o seu corolário, que é a abertura dos serviços próprios das instituições acadêmicas às necessidades do SUS. As simulações da prática médica futura apontam a perspectiva da progressiva não-hospitalização (muitas práticas assistenciais deverão se desenvolver em ambulatórios, na comunidade e nos domicílios). Os cenários de ensino, portanto, devem ser diversificados, agregando-se ao processo, além dos equipamentos de saúde, os equipamentos educacionais e comunitários.

A interação ativa do aluno com a população e profissionais de saúde deverá ocorrer desde o início do processo de formação, proporcionando ao estudante trabalhar sobre problemas reais, assumindo responsabilidades crescentes como agente prestador de cuidados compatíveis com seu grau de autonomia.

Concomitantemente, muitos serviços próprios das instituições acadêmicas seguem lógica própria interna, vinculados preferencialmente às demandas de ensino e pesquisa que às demandas assistenciais reais e à função desses serviços de maior complexidade em oferecer referência e contra-referência para a rede do SUS. Cria-se assim uma clientela cativa, parte da qual poderia ter seguimento na rede básica, e bloqueia-se o acesso a outros que teriam indicação para utilização de recursos mais sofisticados. Esse eixo de mudança tem dois impactos positivos na medida em que aumenta a representatividade da nosologia prevalente nos serviços próprios, ao mesmo tempo em que torna disponível aos gestores do SUS as referências terciária e quaternária.

\section{Vetor 5: diversificação de cenários do processo de ensino}

- Estágio 1: atividades práticas durante os dois primeiros anos do curso estão limitadas aos laboratórios da área básica; ciclo clínico com práticas realizadas majoritariamente em enfermarias hospitalares e com corridas de leito;

- Estágio 2: atividades extramurais isoladas de acadêmicos de medicina em unidades do SUS, durante os dois primeiros anos do curso, com a participação exclusiva ou predominante de professores da área de saúde coletiva, correspondendo a menos de $10 \%$ da carga horária. Ciclo clínico majoritariamente baseado em atividades ambulatoriais em ambulatório pertencente à instituição de ensino que tenha central de marcação de consultas própria, ou em ambulatórios conveniados cuja administração seja apartada da gestão da rede do SUS;

- Estágio 3: atividades extramurais em unidades do SUS, equipamentos escolares e da comunidade, ao longo de toda a carreira, com graus crescentes de complexidade. Durante os dois primeiros anos de graduação, combinam-se as atividades extramurais multiprofissionais com experiências de integração em laboratórios de problematização, com participação de docentes de áreas básicas e clínicas em, pelo menos, $20 \%$ da carga horária. Atividades clínicas desenvolvidas de forma mista entre serviços próprios das IES e unidades comuns e correntes de atenção básica da rede do SUS - majoritariamente ambulatorial, ou em serviços próprios das IES que subordinem suas centrais de marcação de consulta às necessidades locais do SUS - em que se perfaçam menos $40 \%$ da carga horária. Internato desenvolvido em, pelo menos, $25 \%$ na rede do SUS.

\section{Vetor 6: abertura dos serviços universitários às necessidades do SUS}

- Estágio 1: serviços próprios, isolados da rede do SUS, com porta de entrada separada e com clientela cativa e redundante;

- Estágio 2: serviços parcialmente abertos ao SUS, mas preservando algum grau de autonomia na definição de seus pacientes;

- Estágio 3: serviços próprios completamente integrados ao SUS, sem central de marcação de consultas ou de internações próprias das instituições acadêmicas. Desenvolvimento de mecanismos institucionais de referência e de contra-referência com a rede do SUS. 